\title{
Nuclear Polymorphism Induced Genomic Instability in Cluster Bean [Cyamopsis tetragonoloba (L.) Taub.] (Fabaceae)
}

\author{
Girjesh Kumar and Shefali Singh* \\ Plant Genetics Laboratory, Department of Botany, University of Allahabad, Allahabad-211002, India \\ Received September 28, 2017; accepted December 12, 2017
}

\begin{abstract}
Summary Several environmental and mutagenic factors lead to induce nuclear polymorphism like micronuclei $(\mathrm{MN})$ and nuclear buds. $\mathrm{MN}$ are the disintegrated partitioned nuclear or chromosomal fragment. Their occurrence is indicator of genomic instability or chromosomal turmoil. Combined mutagenic treatment of gamma rays and ethyl methane sulphonate (EMS) was experienced to induce formation of MN and nuclear buds in cluster bean [Cyamopsis tetragonoloba (L.) Taub]. A considerable proportion of microcells was also encountered that display future fate of micronuclei in the cell. A peculiar correlation with this nuclear polymorphism was experienced on the presence of bridges and laggards at anaphase I and II stages. Frequency of bridges and laggards were collinear to the combined mutagenic action. Pollen viability was also examined through pollen fertility percentage to inculcate effects of the nuclear incineration on the viability of pollen and the results depicted a dose dependent decline in pollen fertility.
\end{abstract}

Key words Cluster bean, Pollen mother cell, Micronucleus, Microcell, Mutagen, Pollen fertility, Gamma ray, EMS.

Diligency in the cellular processes, specifically of the cell division, is a quintessential pre-requisite for fidelity in inheritance whereas errors may lead to alter the endproducts of meiosis. Acquisition of reports for error in nucleus is a serious ground for concern, since it is the action centre for entire cell expression and is a vestibule for intrinsic hereditary factors. The significance of nucleus can be easily estimated by the fact that enucleated cells have a restricted fate and functioning. In-site nuclear study has assisted in unravelling the hidden mysteries of inheritance; with this, it has also paved the stepping stones for classical genetics. Advent of cytogenetic studies provided testament for nuclear and chromosomal behaviour and also decrypted the influence of mutagenic agents and environmental factors on integrity of these genetical entities. A prominent indicator for mutagenic errors in nucleus is the occurrence of MN that depreciates from the principle nucleus of cell. $\mathrm{MN}$ or the Howell-Jolly bodies, are chromatin-containing structures found in the cytoplasm of cells and are surrounded by a membrane that has no detectable link to the cell nucleus (Schiffmann and De Boni 1991). An outcome of nuclear abstraction, MN may result due to varied consequences. $\mathrm{MN}$ are expressed in dividing cells that either contain chromosome fragments lacking centromere and/or whole chromosomes that are unable to move

\footnotetext{
* Corresponding author, e-mail: shefalisingh.910@gmail.com DOI: 10.1508/cytologia.83.137
}

to the spindle poles (Fenech 2000). According to Schmid (1975), chromosomal damage can be easily accessed by MN measurement. With cell cycle culmination, these fragmented segments or the laggards get enclosed in a separate nuclear membrane, a structure that is $\mathrm{MN}$. It resembles in structure with daughter nucleus although being way smaller in size (Sedelnikova et al. 2007).

Among many forwarded reasons for genesis of MN, laggards and bridges are important, and this argument requires studying the frequency of these two chromosomal aberrations for contemplating about the integration among the three abnormalities. Emanation of bridges and $\mathrm{MN}$ occurs through similar mechanism and henceforth, computation of bridges is of paramount significance to assess the mutagenic genotoxicity level. Nuclear buds, a nuclear polymorphism exhibited as budding or protrusions of nucleus, is another component of abnormalities which is regarded as stable marker of genotoxicity at interphase (Ruddle 1962).

Cluster bean is a splendid leguminous plant used as gum yielding, vegetable and forage crop. The infinite ethnobotanical and nutraceutical possibilities can be elevated using mutagenic strategies since the plant is primarily self-pollinating crop having narrow genetic base. Numerous works is present on the effect of single mutagen however present work is planned to combine physical and chemical mutagen together. For this, combined mutagenic action of gamma rays and EMS was optimized in the present work. Gamma rays are elec- 
tromagnetic radiations with high penetrating strength, enough to cause ionization of atoms and molecules. EMS is a monofunctional alkylating agent and is considered as a potent mutagen and carcinogen (Meuth and Arrand 1982). It has been documented in several previous findings that higher doses of gamma radiation (Verma and Khan 2016) and EMS (Kumar and Chaudhary 2015) lead to $\mathrm{MN}$ induction. The mutation frequency may either increase or decrease when physical and chemical mutagens act independently of each other or compete for the same sites (Srivastav and Raina 1981). Efficiency of physical or chemical mutagen by combining gamma rays and EMS has been significantly worked by Jayabalan and Rao (1988) in tomato where combination led to genetic variation. Cytological study may facilitate for encrypting and imaging the cytogenetical influences of combined mutagenic interaction.

\section{Materials and methods}

\section{Plant system and treatment with mutagens}

Seeds of cluster bean of variety RGC-1038, was procured from CAZRI, Rajasthan, India. Fresh and healthy seeds of cluster bean were selected and kept in five separate airtight plastic packets. The seeds were initially irradiated with ionizing gamma rays at 100, 200, 300, 400 and $500 \mathrm{~Gy}$ from a ${ }^{60} \mathrm{Co}$ source at National Botanical Research Institute, Lucknow with dose rate of $2 \mathrm{~s} \mathrm{~Gy}^{-1}$. After irradiation, pre-soaked seeds of each dose were immersed in $0.3 \%$ EMS in $20 \mathrm{~mL}$ of phosphate buffer of $\mathrm{pH} 7.0$ for $3 \mathrm{~h}$. Few seeds were dipped in distilled water and were regarded as control. Then, the treated seeds were thoroughly washed in distilled water and sown in pots in triplicates along with control. Higher two treatment i.e. 400 and $500 \mathrm{~Gy}+\mathrm{EMS}$ were lethal for plants.

\section{Analysis of meiosis in PMCs and pollen fertility}

Young floral buds were fixed in Carnoy's fixative (1 part glacial acetic acid: 3 parts alcohol). After $24 \mathrm{~h}$ the fixative was decanted and the buds were preserved in $70 \%$ alcohol at $4{ }^{\circ} \mathrm{C}$. For meiotic study, anthers were teased on slide in a drop of alcohol. Furthermore, 2\% acetocarmine was used for chromosomal staining. Slides were observed under an Olympus microscope whereas Nikon microscope was deployed for snapping images at various stages. Pollen fertility percentage was also documented using glycero-acetocarmine stainability test (Marks 1954). Five slides for each treatment set were prepared out of which ten fields of views in each slide were recorded.

\section{Statistical analysis}

A statistical software, SPSS 16.0 was employed for statistical calibration. The data for cytological parameters were analyzed using one way analysis of variance and Duncan's multiple range test; whereas graph was plotted using SigmaPlot 10 (Systat software Inc.).

\section{Results}

Manifestation of cytogenetic study harboured an insight to the chromosomal architecture and number. In control, PMCs with seven bivalents were precisely assembled at equator at metaphase I and anaphase I was witnessed as proper poleward migration of chromosomes (Fig. 1A and B, respectively). Combined treatment, was, however, experienced to have considerable implications on chromosomal morphology. A range of different abnormalities were recorded, of which MN formation was of serious concern. At the lowest dose $(100 \mathrm{~Gy}+0.3 \%$ EMS $)$, percent frequency of MN recorded was $2.18 \pm 0.25 \%$ which was calculated to be $3.93 \pm 0.45 \%$ at $200 \mathrm{~Gy}+0.3 \%$ EMS, which increased up to $7.56 \pm 0.32 \%$ at highest combined treatment (300 Gy+0.3\% EMS) (Table 1).

Table 2 is a representation of total MN frequency in relation to number of accessory $\mathrm{MN}$. This data is representation of the total $\mathrm{MN}$ frequency recorded for $100 \mathrm{~Gy}+0.3 \%$ EMS to $300 \mathrm{~Gy}+0.3 \%$ EMS treatment. Mono-micronucleate condition was found at all the three treatment sets in highest frequency and was recorded to ascend from $1.42 \pm 0.27 \%$ at $100 \mathrm{~Gy}+0.3 \%$ EMS to $3.14 \pm 0.19 \%$ at $300 \mathrm{~Gy}+0.3 \%$ EMS set. Binucleate frequency increased from $0.76 \pm 0.08$ to $1.96 \pm 0.37 \%$ from lower to higher treatment set. Least frequency was computed for pentanucleate condition; it was evidenced at highest treatment set only and calculated to be $0.59 \pm 0.30 \%$. Besides $\mathrm{MN}$, a considerable frequency of laggards (Fig. 1K) and bridges were retrieved that display integration with $\mathrm{MN}$ formation. Percent frequency of laggards at anaphase increased from $0.53 \pm 0.28 \%$ at $100 \mathrm{~Gy}+0.3 \%$ EMS to $3.03 \pm 0.16 \%$ at $300 \mathrm{~Gy}+0.3 \% \mathrm{EMS}$. Anaphase bridges were absent at lower combined treatment but recorded at $200 \mathrm{~Gy}+0.3 \%$ EMS $(0.91 \pm 0.17 \%)$ and $300 \mathrm{~Gy}+0.3 \%$ EMS treatment sets $(1.85 \pm 0.18 \%)$. Partitioning and enucleation of MN from parent cell occurred via microcell, as evidenced in Fig. 1L-O. It was perceived that formation of microcell was seen at the highest two treatment sets i.e., $200 \mathrm{~Gy}+0.3 \% \mathrm{EMS}(0.43 \pm 0.08 \%)$ and $300 \mathrm{~Gy}+0.3 \%$ EMS $(1.53 \pm 0.36 \%)$. Pollen fertility criterion was also adjudged to assess the impact of combined mutagenic action on viability of pollens. It was perceived that in case of control, pollens were eminently stained globose nucleated entity, whereas sterile pollens were sparsely stained and shrunken. Highest pollen fertility was recorded in control set that went for a continuous decline with respect to each increasing treatment. It was calculated to be calculated $97.33 \pm 0.88 \%$ in case of control which declined up to $70 \pm 1.15 \%$ at the highest treatment set. Fig. 2 depicts graphical representation of the Pollen fertility trend in the control as well as treated sets. Fig. 1P displays sterile pollens. 


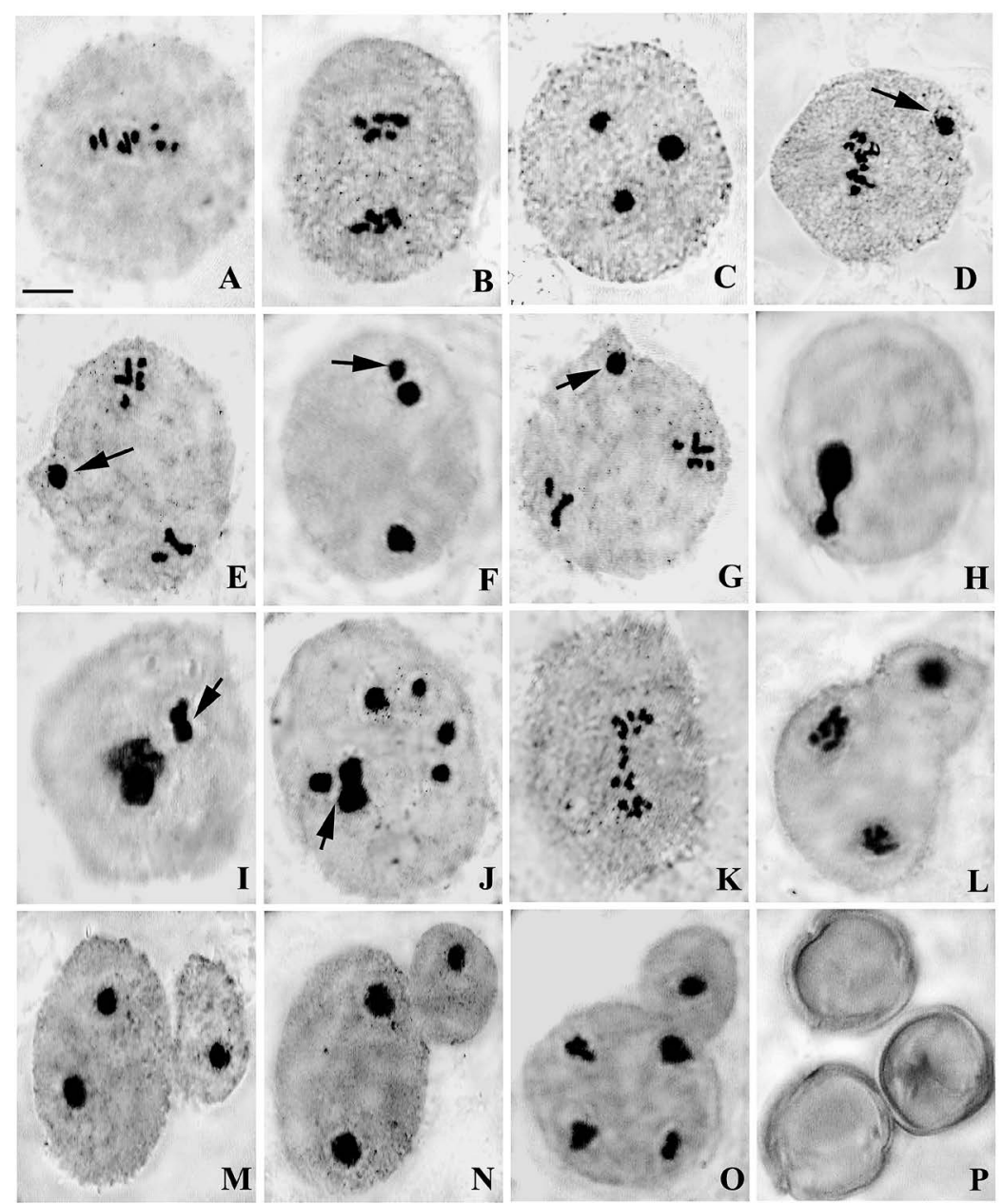

Fig. 1. Meiotic cells of control and treated plants. A: normal metaphase I; B: normal anaphase I; C: prophase I with $2 \mathrm{MN}$; D: metaphase I with MN; E: anaphase I with MN; F: telophase I with MN; G: metaphase II with MN; H: nuclear budding; I: prophase with I nuclear bleb; J: multinucleate PMC with budding; K: laggards at anaphase; L: microcell at Anaphase I; M: microcell at telophase I; N: microcell; O: microcell at anaphase II; P: sterile pollens. Scale bar $=9.5 \mu \mathrm{m}$.

Table 1. Frequency of micronuclei induced by combined treatment of gamma rays and EMS in cluster bean.

\begin{tabular}{lccc}
\hline \hline Treatment & Total number of PMCs (Mean) & Number of PMCs with MN (Mean \pm S.E.) & PMCs with MN \% (Mean \pm S.E.) \\
\hline Control & 309.33 & 0 & 0 \\
$100 \mathrm{~Gy}+0.3 \%$ EMS & 303.33 & $6.66 \pm 0.88$ & $2.18 \pm 0.25$ \\
200 Gy+0.3\% EMS & 300.33 & $11.66 \pm 1.20$ & $3.93 \pm 0.45$ \\
$300 \mathrm{~Gy}+0.3 \%$ EMS & 286.33 & $21.66 \pm 1.20$ & $7.56 \pm 0.32$ \\
\hline
\end{tabular}

S.E. $=$ Standard Error.

Table 2. Configuration of MN in relation to number of nuclei alongwith anaphase abnormalities in cluster bean.

\begin{tabular}{lcccccccc}
\hline \hline \multirow{2}{*}{ Treatment } & \multicolumn{4}{c}{ Number of MN per PMC (Mean \pm S.E.) } & & $\begin{array}{c}\text { Number of anaphase cells } \\
\text { (Mean } \pm \text { S.E.) }\end{array}$ & $\begin{array}{c}\text { Number of } \\
\text { microcell } \\
\text { (Mean } \pm \text { S.E.) }\end{array}$ \\
\cline { 2 - 7 } & Mononucleate & Binucleate & Trinucleate & Tetranucleate & Pentanucleate & Laggards I/II & Bridges I/II & 0 \\
\hline Control & 0 & 0 & 0 & 0 & 0 & 0 & 0 & 0 \\
$100 \mathrm{~Gy}+0.3 \%$ EMS & $1.42 \pm 0.27$ & $0.76 \pm 0.08$ & 0 & 0 & 0 & $0.53 \pm 0.28$ & 0 & 0 \\
$200 \mathrm{~Gy}+0.3 \%$ EMS & $1.92 \pm 0.26$ & $1.11 \pm 0.10$ & $0.40 \pm 0.27$ & $0.47 \pm 0.24$ & 0 & $1.69 \pm 0.25$ & $0.91 \pm 0.17$ & $0.43 \pm 0.08$ \\
$300 \mathrm{~Gy}+0.3 \%$ EMS & $3.14 \pm 0.19$ & $1.96 \pm 0.37$ & $1.04 \pm 0.03$ & $0.81 \pm 0.09$ & $0.59 \pm 0.30$ & $3.03 \pm 0.16$ & $1.85 \pm 0.18$ & $1.53 \pm 0.36$ \\
\hline
\end{tabular}




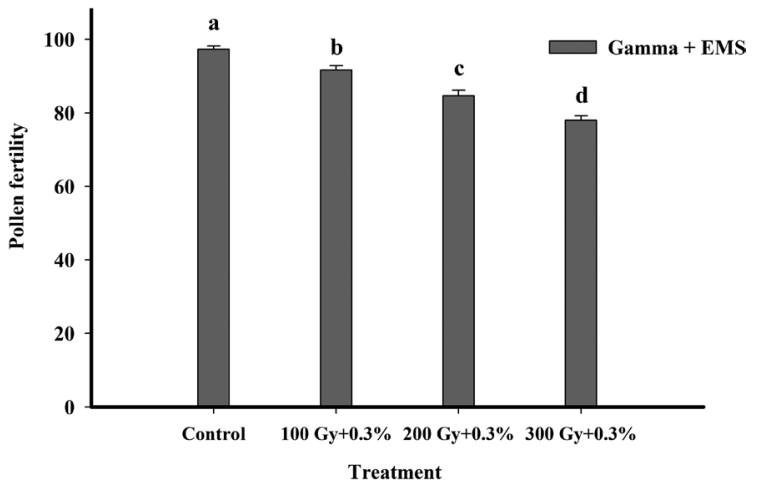

Fig. 2. Graphical account on pollen fertility percentage in cluster bean after combined treatment of mutagens.

\section{Discussion}

Ever since the pioneering works on the concept of $\mathrm{MN}$, consequences and repercussions, linked with it have been investigated and several theories have been thereafter forwarded. Critical evaluation of recent reports asserts that $\mathrm{MN}$ may result due to obliteration of cell cycle via clastogenic or aneugenic effects (Walker et al. 1996). Clastogenic attack introduces breaks in chromosomes while aneugen affects cell division and spindle properties resulting in aneuploidy (Luzhna et al. 2013).

Gernand et al. (2005) opined that MN are products of miss-repaired or unrepaired DNA double stranded breaks. This plausibly has occurred due to the combination of two mutagens where physical and chemical mutagen complements each other. This co-action is termed as synergistic interaction. The synergism occurs firstly because of first mutagen treatment making accessible otherwise non available sites for reaction to the second mutagen; and secondly pre-mutational lesions induced by first mutagen becomes fixed due to inhibitory effect of the second mutagen on repair enzyme (Payez and Deering 1972). Patil and Bhatia (1992) reported that the localization of breaks along the chromosomes result from the affinity of EMS for guanine rich areas on the other hand the radiations can have direct effect on chromosomes. It implies that the two mutagens complement each other, where gamma rays introduce direct damage to DNA molecule and EMS advances to cause chemical modification of bases.

Fenech et al. (2011) cited that main mechanism of $\mathrm{MN}$ formation is hypomethylation of centromeric and paracentromeric satellite repeats in human lymphocyte culture. It may also be derived by processes such as polyploidization, in which they originate from the elimination of exceeding DNA of the main nucleus in an attempt to restore the normal conditions of ploidy in A. cepa (Fernandes et al. 2007). According to Terradas et al. (2009), MN might be involved in DNA damage responses. It is reported that $\mathrm{MN}$ is able to synthesize its own DNA (Kramer et al. 1990) for restoration of the damage, albeit there is asynchrony in the level of progression among the parent nucleus and MN. Presence or absence of nuclear pore complex together with the specific micronuclear DNA content might be decisive factors for the transcriptional activity of MN (Hoffelder et al. 2004).

Among other polymorphic structures of nucleus, nuclear buds are significant that are marked as nuclear protrusions. Fig. 1H displays nuclear bud. Furthermore, remnants of broken nucleoplasmic bridges may also descend into buds (Utani et al. 2010). Synchronised segregation of chromosomes requires fidelity in the alliance of centromeric components with the kinetochore complex. Vázquez-Diez et al. (2016) attributed that misattachment of kinetochore leads to laggards that outcomes into MN formation. Mutagenic action also incidences into chromosomal errors leading to breaks and formation of bridges. Bridges originate from dicentric chromosomes that are formed through miss repair of DNA breaks and telomere fusion events (Fenech et al. 2011). Effect of mutagen was also witnessed on pollen fertility. Darkly stained pollens grains were judged as fertile whereas lighter stained pollens were regarded as sterile. Chromosomal alterations and abnormal meiosis compounded to cause sterility of pollens.

Disintegration of the MN from the parent nucleus occurs via formation of microcells. Formation of microcell has also been reported in leguminous crop, Sunn hemp (Kumar and Dwivedi 2016). It consists of a single MN and a thin rim of cytoplasm surrounded by an intact plasma membrane in animal cells (Sekiguchi et al. 1978). Microcell mediated chromosome transfer serve an ingenious purpose of genetic mapping and may be reciprocated for the identification of a disease-bearing chromosome (Whitney et al. 1995). Its creation is a process of enucleation, henceforth it can be envisioned that a microcell might single out certain intrinsic hereditary factors along with it leaving behind a deficient cell.

Human carcinogenic predictions associated with MN (Bonassi et al. 2007) have made it noteworthy for biomonitoring. MN designates genomic instability whereas its occurrence denotes a passage that genome tends to undergo nuclear restitution. The underlining repercussion of MN is aneuploidy (Seoane et al. 2000). Microcell creation mediated enucleation may lead to paradigm shift in studying tumorigenic course and inheritance loss instilled through genetic ailments.

\section{Acknowledgements}

Authors express their gratitude to NBPGR and its regional station Central Arid Zone Research Institute (CAZRI, Rajasthan) for providing seeds of cluster bean. Thanks are also due to the members of Plant Genetics Laboratory for their valuable help and guidance. 


\section{References}

Bonassi, S. et al. 2007. An increased micronucleus frequency in peripheral blood lymphocytes predicts the risk of cancer in humans. Carcinogenesis 28: 625-631.

Fenech, M. 2000. The in vitro micronucleus technique. Mutat. Res. 455: 81-95.

Fenech, M., Kirsch-Volders, M., Natarajan, A. T., Surralles, J., Crott, J. W., Parry, J., Norrpa, H., Eastmond, D. A., Tucker, J. D. and Thomas, P. 2011. Molecular mechanisms of micronucleus, nucleoplasmic bridge and nuclear bud formation in mammalian and human cells. Mutagenesis 26: 125-132.

Fernandes, T. C. C., Mazzeo, D. E. C. and Marin-Morales, M. A. 2007. Mechanism of micronuclei formation in polyploidizated cells of Allium cepa exposed to trifluralin herbicide. Pestic. Biochem. Physiol. 88: 252-259.

Gernand, D., Rutten, T., Varshney, A., Rubtsova, M., Prodanovic, S., Bruss, C., Kumlehn, J., Matzk, F. and Houben, A. 2005. Uniparental chromosome elimination at mitosis and interphase in wheat and pearl millet crosses involves micronucleus formation, progressive heterochromatinization, and DNA fragmentation. Plant Cell 17: 2431-2438.

Hoffelder, D. R., Luo, L., Burke, N. A., Watkins, S. C., Gollin, S. M. and Saunders, W. S. 2004. Resolution of anaphase bridges in cancer cells. Chromosoma 112: 389-397.

Jayabalan, N. and Rao, G. R. 1988. Cytological effects of single and combination treatments of physical and chemical mutagens on tomato. Cytologia 53: 601-605.

Kramer, J., Schaich-Walch, G. and Niisse, M. 1990. DNA synthesis in radiation-induced micronuclei studied by bromodeoxyuridine (BrdUrd) labelling and anti-BrdUrd antibodies. Mutagenesis 5: 491-495.

Kumar, G. and Chaudhary, N. 2015. Nuclear blebs assay for genome instability in Phaseolus vulgaris L. Cytologia 80: 505-512.

Kumar, G. and Dwivedi, S. 2016. Induced nuclear pleomorphism in pollen mother cells of Crotalaria juncea L. (sunnhemp). Cytologia 81: 323-327.

Luzhna, L., Kathiria, P. and Kovalchuk, O. 2013. Micronuclei in genotoxicity assessment: from genetics to epigenetics and beyond. Front. Genet. 4: 1-17.

Marks, G. E. 1954. An aceto-carmine glycerol jelly for use in pollenfertility counts. Stain Technol. 29: 277.

Meuth, M. and Arrand, J. E. 1982. Alterations of gene structure in ethyl methane sulfonate induced mutants of mammalian cells. Mol. Cell. Biol. 2: 1459-1462.

Patil, B. and Bhat, G. I. 1992. A comparative study of MH and EMS in the induction of chromosomal aberrations on lateral root meristem in Clitoria ternatea L. Cytologia 57: 259-264.

Payez, J. F. and Deering, R. A. 1972. Synergistic and antagonistic effects of caffeine on two strains of cellular slime mold treated with alkylating agents. Mutat. Res. 16: 318-321.

Ruddle, F. H. 1962. Nuclear bleb: A stable interphase marker in established line of cells in vitro. J. Natl. Cancer Inst. 28: 1247-1251.

Schiffmann, D. and De Boni, U. 1991. Dislocation of chromatin elements in prophase induced by diethylstilbestrol: a novel mechanism by which micronuclei can arise. Mutat. Res. 246: 113-122.

Schmid, W. 1975. The micronucleus test. Mutat. Res. 31: 9-15.

Sedelnikova, O. A., Nakamura, A., Kovalchuk, O., Koturbash, I., Mitchell, S. A., Marino, S. A., Brenner, D. J. and Bonner, W. M. 2007. DNA double strand breaks form in bystander cells after microbeam irradiation of three dimensional human tissue models. Cancer Res. 67: 4295-4302.

Sekiguchi, T., Shelton, K. and Ringertz, N. R. 1978. DNA content of microcells prepared from rat kangaroo and mouse cells. Exp. Cell Res. 113: 247-258.

Seoane, A. I., Güerci, A. M. and Dulout, F. N. 2000. Mechanisms involved in the induction of aneuploidy: the significance of chromosome loss. Genet. Mol. Biol. 23: 1077-1082.

Srivastav, P. K. and Raina, S. N. 1981. Cytogenetics of Tephrosia II. Mutagenic effect of single, pre and postirradiation treatments with EMS and MMS in Tephrosia purpurea. Cytologia 46: 709-721.

Terradas, M., Martin, M., Tusell, L. and Genesca, A. 2009. DNA lesions sequestered in micronuclei induce a local defective-damage response. DNA Repair 8: 1225-1234.

Utani, K., Kohno, Y., Okamoto, A. and Shimizu, N. 2010. Emergence of micronuclei and their effects on the fate of cells under replication stress. PLoS One 5: 1-12.

Vázquez-Diez, C., Yamagata, K., Trivedi, S., Haverfield, J. and FitzHarris, G. 2016. Micronucleus formation causes perpetual unilateral chromosome inheritance in mouse embryos. Proc. Natl. Acad. Sci. U.S.A. 113: 626-631.

Verma, R. C. and Khan, M. A. 2016. Assessment of gamma rays induced cytotoxicity in common wheat (Triticum aestivum L.). Cytologia 81: 41-45.

Walker, J. A., Boreham, D. R., Unrau, P. and Duncan, A. M. V. 1996. Chromosome content and ultrastructure of radiation-induced micronuclei. Mutagenesis 11: 419-424.

Whitney, M., Thayer, M., Reifsteck, C., Olson, S., Smith, L., Jakobs, P. M., Leach, R., Naylor, S., Joenje, H. and Grompe, M. 1995. Microcell mediated chromosome transfer maps the Fanconi anaemia group D gene to chromosome 3 p. Nat. Genet. 11: 341-343. 